Caroline Menta ${ }^{1,2}$

(D) https://orcid.org/0000-0003-3401-8949

Luísa Weber Bisol

Ohttps://orcid.org/0000-0002-8657-8801

Eduardo Lopes Nogueira',2

@inttps://orcid.org/0000-0001-5748-7970

Paula Engroff1,2

(- https://orcid.org/0000-0002-3639-545X

Alfredo Cataldo Neto $0^{1,2}$

Ohttps://orcid.org/0000-0002-8082-1866

\section{Prevalence and correlates of generalized anxiety disorder among elderly people in primary health care}

\author{
Prevalência e correlatos do transtorno de ansiedade generalizada \\ em idosos atendidos em atenção primária
}

DOl: $10.1590 / 0047-2085000000267$

\begin{abstract}
Objective: To examine the prevalence of generalized anxiety disorder (GAD) and its associations with sociodemographic and health factors. Methods: A cross-sectional study with a population-based sample of 578 individuals aged 60 years or older from the Family Health Strategy (FHS) program of Porto Alegre, RS, Brazil. Home visit screening and general data collection were made by trained Community Health Workers (CHWs). Diagnoses of psychiatric disorders were made by board-certified psychiatrists using the Mini International Neuropsychiatric Interview plus (MINIplus) in the Hospital São Lucas of the Pontifical University of Rio Grande do Sul (PUCRS). Results: GAD was found in 9\% of the sample ( $\mathrm{n}=52 ; \mathrm{Cl} 95 \%=$ 6.9-11.6). The main results of the multivariate analysis show associations between GAD and retirement (PR: 0.43, Cl: 0.25-0.76), history of falls (PR: 2.52, Cl: 1.42-4.49), cohabitation with four or more people (PR: 1.80, Cl: 1.04-3.13), having more than one hospitalization in the last year (PR: 2.53, Cl: 1.17-5.48) and self-perception of health as regular (PR: 2.75, Cl: 1.02-7.47). Retirement in the elderly shows $2.32 x$ less risk of GAD, although confounding factors may have overestimated this finding and underestimated the association with female gender (PR: 1.61, Cl: 0.83-3.10). Conclusions: We estimate a high prevalence of GAD in this population. Associations were found between GAD and health self-perceived as regular, cohabitation with four or more people, history of falls and more than one hospitalization in the last year. These epidemiological data from the Family Health Strategy are important to develop further strategies for this age group that could improve the health care practice.
\end{abstract}

\section{KEYWORDS}

Aged, anxiety disorders, generalized anxiety disorder, epidemiology, primary health care, public health.

\section{RESUMO}

Objetivo: Examinar a prevalência do transtorno de ansiedade generalizada (TAG) em idosos e suas associações com fatores sociodemográficos e de saúde. Métodos: Estudo transversal, composto por uma amostra de base populacional de 578 indivíduos com 60 anos ou mais, participantes do programa Estratégia Saúde da Família (ESF) de Porto Alegre, RS, Brasil. Agentes de saúde treinados realizaram coleta de dados dos indivíduos durante as visitas domiciliares. A avaliação diagnóstica psiquiátrica foi realizada por psiquiatras, no Hospital São Lucas da Pontifícia Universidade Católica do Rio Grande do Sul (PUCRS), por meio da aplicação do Mini International Neuropsychiatric Interview plus (MINIplus). Resultados: O TAG foi encontrado em 9\% ( $n=52 ;$ IC 95\% =6,9-11,6) da amostra. Os principais resultados da análise multivariada evidenciaram associações entre TAG e aposentadoria (RP: 0,43; IC: 0,25-0,76), história de quedas (RP: 2,52; IC: 1,42-4,49), coabitação com quatro ou mais pessoas (RP: 1,80; IC: 1,04-3,13), ter mais de uma hospitalização no último ano (RP: 2,53, IC: 1,17-5,48) e autopercepção de saúde avaliada como regular (RP: 2,75, IC: 1,02-7,47). Idosos aposentados apresentaram risco 2,32 menor de TAG, embora fatores confundidores possam ter superestimado esse achado e subestimado a associação com gênero feminino (RP: 1,61; IC: 0,83-3,10). Conclusões: Estimou-se uma alta prevalência de TAG nessa população de idosos. Foram encontradas associações de TAG com autopercepção de saúde regular, coabitação com quatro ou mais pessoas, mais de uma hospitalização no último ano e história de quedas. Esses dados oriundos da Estratégia Saúde da Família são importantes para o desenvolvimento de estratégias adicionais que possam melhorar a prática de assistência à saúde na população idosa.

\section{PALAVRAS-CHAVE}

Idoso, transtornos ansiosos, transtorno de ansiedade generalizada, epidemiologia, atenção primária à saúde, saúde pública.

Received in: Apr/7/2020. Approved in: Apr/7/2020

1 Pontifical Catholic University of Rio Grande do Sul (PUCRS), Hospital São Lucas, Porto Alegre, RS, Brazil.

2 Pontifical Catholic University of Rio Grande do Sul (PUCRS), Institute of Geriatrics and Gerontology (IGG), Postgraduate Program in Biomedical Gerontology, Porto Alegre, RS, Brazil. 


\section{INTRODUCTION}

The acceleration of population aging is a global phenomenon, and as such, it is very important to direct investigations towards the most prevalent neuropsychiatric diseases among the elderly'. Anxiety disorders, although frequent in this population, are usually understudied and underdiagnosed in seniors ${ }^{2}$. The diagnoses of anxiety and depression in the primary care system are poor, just 23\% of pure anxiety cases are recognized when compared with $56 \%$ of depression cases $^{3}$.

Generalized anxiety disorder (GAD) is the most common anxiety disease in the elderly ${ }^{4}$. It is characterized by unusually excessive worry, associated with a feeling of restlessness, feeling keyed up, muscle tension and reactive behavior that attempt to reduce worry or emotional distress, such as avoidance ${ }^{5}$. Its prevalence varies from 1.2 to $7.3 \%$ in community-dwelling elderly ${ }^{2,6}$. This disorder causes important negative impacts that lead to high and chronic psychological suffering and impairs quality of life, as well as professional and personal performance ${ }^{7}$. Even so, population-based studies on anxiety are relatively scarce in Latin America. Thus, the aim of this study is to estimate the prevalence of GAD and examine its associations with sociodemographic and health factors.

\section{METHODS}

This cross-sectional population-based survey is part of a larger project "The multidimensional study of the elderly in the FSH in Porto Alegre, Brazil (EMI-SUS)", focused to show the elderly population's health problems. Data were gathered between March 2011 and December 2012 from a random sample of older adults (60 years or more) users of the Family Health Strategy (FSH), a public health facility, in Porto Alegre, RS, Brazil. In 2010, when the protocol was carried out, the municipality had 22,000 seniors registered in 97 family health teams (FHT), distributed into 8 health districts (HD). Considering possible sample losses and exclusions, 30 FHT were selected through stratified random sampling and 36 older adults were selected for each team, a total sample of 1,080 seniors. The "sample.exe", program of the PEPI for DOS statistical package (version 4) was used to calculate the sample size of GAD in elderly people and a 0.05 was selected as a significance level. The minimum sample size was 569 , considering $2 \%$ of the acceptable error to an expected prevalence from $6.5 \%$ of GAD in seniors 9 . The study consisted of 1) home visits to collect sociodemographic data and validated screening evaluations for depression, alcohol misuse and cognitive impairment conducted by trained Community Health Workers (CHWs); 2) blind specialized evaluations conducted by board-certified psychiatrists in the Hospital São Lucas of the Pontifical University of Rio Grande do Sul (PUCRS) to assess current and lifetime diagnosis of psychiatric disorders using the Brazilian version of Mini International Neuropsychiatric Interview 5.0.0 Plus (MINIplus). Of 1,080 randomly selected seniors, the CHWs located 809 alive and residing at their registered addresses. Out of those, 621 headed to the hospital for evaluation and complete MINIplus dada was gathered from 578 , which were included in this analysis.

The dependent variable examined was the GAD diagnosis based on DSM-IV criteria. Frequencies were used to describe the sample and estimate prevalence with a confidence interval (Cl) of 95\%. Pearson's chi-square test was used to verify associations and the Poisson regression was used to improve the analysis and control confounding factors. All variables were initially included in the controlled analysis and those with less significance were excluded oneby-one to achieve the final model. A predetermined level of 0.05 was considered and calculations were performed using the software SPSS 17.

This study was approved by the PUCRS ethics committee (10/04967) and the Public Health Department of the city of Porto Alegre (registration: 499/process: 001.021434.10.7) All participants or their legal representatives signed an informed consent.

\section{RESULTS}

The total sample was comprised of 578 individuals and was characterized by a predominance of women $(63.8 \%, n=$ $369)$, younger elderly (62.4.\%, $n=337)$, illiteracy or very poor schooling (61.6\%, $n=356)$, and low income (93.2\%, $n=507)$. The prevalence of GAD was $9 \%(n=52, \mathrm{Cl}$ : 6.9-11.6).

Table 1 shows the variation frequencies of GAD in relation to sociodemographic characteristics, self-perceived health, history of hospitalization in the past 12 months and history of falls. The main uncontrolled findings show higher frequencies of GAD in female gender 10.8\% ( $n=40, p=0.04)$, 60-69 age group 11\% $(n=37, p=0.047)$, not retired $17.7 \%$ ( $n=26, p=0.001)$, cohabitation with 4 or more people $11.9 \%(n=33, p=0.019)$, and history of falls $18.8 \%(n=40$, $\mathrm{p}=0.003)$.

Table 2 presents multivariate results using the Poisson regression with a robust estimation of Prevalence Ratios (PR) that are discussed below.

\section{DISCUSSION}

A high prevalence of GAD was estimated; the result is superior to what is described in the literature, which varies from 1.2\% to $7.3 \%$, 2, possibly because of different methodological and 
Table 1. Distribution of sociodemographic and health characteristics and the prevalence of generalized anxiety disorder (GAD) according to these variables on 578 elderly evaluated by the Porto Alegre's Family Health Strategy (FHS), Brazil, 2012

\begin{tabular}{|c|c|c|c|}
\hline \multirow{2}{*}{ Variable } & \multirow{2}{*}{$\begin{array}{c}\text { Population } \\
\text { n (\%) }\end{array}$} & \multicolumn{2}{|c|}{ GAD' } \\
\hline & & $\%$ & $p^{2}$ \\
\hline \multicolumn{4}{|l|}{ Gender } \\
\hline Male & 209 (36.2) & 5.7 & 0.040 \\
\hline Female & $369(63.8)$ & 10.8 & \\
\hline \multicolumn{4}{|l|}{ Age } \\
\hline $60-69$ years & 337 (62.4) & 11.0 & 0.047 \\
\hline$\geq 70$ years & $203(37.6)$ & 5.9 & \\
\hline \multicolumn{4}{|l|}{ Years of schooling } \\
\hline Illiterates & $147(25.4)$ & 8.8 & 0.653 \\
\hline $1-4$ years & 209 (36.2) & 8.1 & \\
\hline $5-8$ years & $173(29.9)$ & 9.8 & \\
\hline$>8$ years & $49(8.5)$ & 10.2 & \\
\hline \multicolumn{4}{|l|}{ Race/ethnicity } \\
\hline White & $369(65.0)$ & 10.0 & 0.229 \\
\hline Multiracial (Brown) & $77(13.6)$ & 9.1 & \\
\hline Afro-Brazilian & $106(18.7)$ & 4.7 & \\
\hline Others (Indigenous and oriental) & $16(2.8)$ & 12.5 & \\
\hline \multicolumn{4}{|l|}{ Marital status } \\
\hline Married & $215(37.7)$ & 10.7 & 0.544 \\
\hline Separated & $93(16.3)$ & 9.7 & \\
\hline Single & $100(17.5)$ & 3.0 & \\
\hline Widowed & $163(28.5)$ & 10.4 & \\
\hline \multicolumn{4}{|l|}{ Lives with life partner } \\
\hline No & $295(51.7)$ & 8.8 & 0.960 \\
\hline Yes & $276(48.3)$ & 8.7 & \\
\hline \multicolumn{4}{|l|}{ Retired } \\
\hline No & $177(31.9)$ & 14.7 & 0.001 \\
\hline Yes & $377(68.1)$ & 6.1 & \\
\hline \multicolumn{4}{|l|}{ Number of people in cohabitation } \\
\hline $1-3$ & $301(52.1)$ & 6.3 & 0.019 \\
\hline$\geq 4$ & $277(47.9)$ & 11.9 & \\
\hline \multicolumn{4}{|l|}{ Personal income (minimum salary) ${ }^{3}$} \\
\hline No income & $44(8.1)$ & 9.1 & 0.972 \\
\hline Up to 2 salaries & $463(85.1)$ & 9.3 & \\
\hline More than 2 salaries & $37(6.8)$ & 8.1 & \\
\hline \multicolumn{4}{|l|}{ Religion } \\
\hline Catholic & $374(65.7)$ & 8.8 & 0.972 \\
\hline Protestant & $115(20.2)$ & 9.6 & \\
\hline Others & $65(11.4)$ & 7.7 & \\
\hline agnostic/atheist & $15(2.6)$ & 3.9 & \\
\hline \multicolumn{4}{|l|}{ Self-perceived health } \\
\hline Excellent/Good & $56(9.9)$ & 10.7 & 0.328 \\
\hline Regular & $312(54.9)$ & 9.9 & \\
\hline Poor/Nery poor & $200(35.2)$ & 7.5 & \\
\hline \multicolumn{4}{|l|}{ Hospitalization last year } \\
\hline No & $476(84.0)$ & 8.2 & 0.004 \\
\hline Once & $66(11.6)$ & 9.1 & \\
\hline More than once & $25(4.4)$ & 28.0 & \\
\hline \multicolumn{4}{|l|}{ History of falls } \\
\hline No & $351(62.6)$ & 6.3 & 0.003 \\
\hline Yes & 210 (37.4) & 18.8 & \\
\hline TOTAL & $578(100)$ & 9,0 & \\
\hline
\end{tabular}

${ }^{1}$ Generalized anxiety disorder.

${ }^{2}$ Based on the Chi-square test.

${ }^{3}$ The minimum salary is the lowest legal monthly income for an employee in Brazil. The amount is set by the government and was approximately $\$ 300$ (US dollars).

In bold the $p$ value with a statistically significant difference.

Prevalence of $\mathrm{GAD}=9,0(\mathrm{n}=52)$. $\mathrm{Cl}$ (confidence interval) $95 \%=6,9-11,6$.
Table 2. Final multivariate analysis model, with Poisson regression, from sociodemographic and health variables in relation with generalized anxiety disorder (GAD) in 578 elderly evaluated by the Porto Alegre's Family Health Strategy (FHS), Brazil, 2012

\begin{tabular}{|c|c|c|c|}
\hline \multirow{2}{*}{ Variable } & \multicolumn{3}{|c|}{ GAD' $^{1}$} \\
\hline & $\mathbf{P R}^{2}$ & $\mathrm{Cl}^{3} \mathbf{9 5 \%}$ & $p$ \\
\hline \multicolumn{4}{|l|}{ Gender } \\
\hline Male & 1 & - & 0.158 \\
\hline Female & 1.61 & $0.83-3.10$ & \\
\hline \multicolumn{4}{|l|}{ Age } \\
\hline $60-69$ years & 1 & - & 0.221 \\
\hline$\geq 70$ years & 0.66 & $0.34-1.28$ & \\
\hline \multicolumn{4}{|l|}{ Race/Ethnicity } \\
\hline White & 1 & - & \\
\hline Multiracial (Brown) & 0.84 & $0.38-1.87$ & 0.667 \\
\hline Afro-Brazilian & 0.67 & $0.27-1.67$ & 0.395 \\
\hline Others (Indigenous and oriental) & 2.17 & $0.61-7.70$ & 0.230 \\
\hline \multicolumn{4}{|l|}{ Retired } \\
\hline No & 1 & - & 0.004 \\
\hline Yes & 0.43 & $0.25-0.76$ & \\
\hline \multicolumn{4}{|l|}{ Number of people in cohabitation } \\
\hline $1-3$ & 1 & - & \\
\hline$\geq 4$ & 1.80 & $1.04-3.13$ & 0.037 \\
\hline \multicolumn{4}{|l|}{ History of falls } \\
\hline No & 1 & - & \\
\hline Yes & 2.52 & $1.42-4.49$ & 0.002 \\
\hline \multicolumn{4}{|l|}{ Hospitalization last year } \\
\hline No & 1 & - & \\
\hline Once & 1.18 & $0.47-2.95$ & 0.721 \\
\hline More than once & 2.53 & $1.17-5.48$ & 0.019 \\
\hline \multicolumn{4}{|l|}{ Self-perceived health } \\
\hline Excellent/Very good & 1 & - & \\
\hline Regular & 2.75 & $1.02-7.47$ & 0.047 \\
\hline Poor/Nery poor & 1.93 & $0.66-5.66$ & 0.232 \\
\hline
\end{tabular}

${ }^{1}$ Generalized anxiety disorder.

2 Prevalence ratios.

${ }^{3}$ Confidence interval.

In bold the $p$ value with statistically significant difference.

diagnostic approaches ${ }^{10}$. Women received the diagnosis more frequently than men (10.8\% versus 5.7\%), as observed in literature 9 . On the other hand, this association lost significance in the controlled analysis (PR: 1.61, Cl: 0.833.10), but a tendency was observed. An explanation for this attenuation when comparing gender could be in a collinear interference with other stronger associations: women have a higher history of falls (44\% versus $27 \%, p \leq 0.001$ ) and lower retirement rates $(64.5 \%$ versus $74.5 \%, p=0.014)$.

Regarding age, older individuals presented GAD less frequently (5.9\% versus $11 \%)$, contrary to the high prevalence of $10.6 \%$ observed in a study with people aged 85 or older ${ }^{11}$.

Retirement reduces by $2.32 x$ the probability of GAD diagnosis ( $p=0.004$ ). Two influences could contribute to this finding: 1) women may be less likely to answer this question correctly because they possibly consider that they never worked officially; and 2) retired people possibly have no work pressure and can better structure a social life for 
themselves, enjoying activities that before retirement, they didn't have time to practice, leading to lower rates of anxiety. Another unexpected result was the 1.8x increase in GAD among elders that live with 4 or more people. In Brazil, family members with low income often depend financially on retired elderly, which may increase the chances of stress and even financial violence; certainly, this association deserves a more specific analysis to examine the patterns implicit in these complex relationships.

The severe course of GAD can lead to higher service rates $^{12}$. Most studies have been focused on the link between psychiatric disorders (depression and less frequent, panic disorder and post-traumatic stress disorder) and health service utilization, and they are not specific for elderly people ${ }^{13,14}$. However, there are insufficient populationbased studies that show associations between GAD and hospitalization admission. The longitudinal EPIC-Norfolk study, a population-based study, showed that participants with GAD comorbid with major depressive disorder had a higher risk for hospital admissions ${ }^{12}$. Although our study evidenced an increase of 2.53x of GAD among seniors who were hospitalized more than once last year $(p=0.019)$, future research needs to examine the reasons for the increased GAD in this particular population, since the major depressive disorder diagnosis was excluded in our sample.

The Poisson regression revealed that the individuals who had a history of falls increased the probability of GAD (PR: 2.52, 95\% Cl: 1.42-4.49); as we can observe the results from a meta-analysis that indicated a significant positive association between anxiety symptoms and falls. Individuals who reported elevated levels of anxiety were 1.53 times more likely to have a fall than those who did not (95\% Cl: 1.28-1.83, $p<0.001)^{15}$. Further studies are important to establish the causal relationship through which anxiety might perform as a risk factor for falls. However, Friedman researched a positive feedback loop created by anxiety symptoms and falls, whereby anxiety increases fall risk, and following falls events increase anxiety symptoms ${ }^{16}$.

Even if the causal relationship was not examined in the cross-sectional design, the increase in GAD diagnosis associated with poorer health, as in the case of a history of falls and hospitalizations, could be expected since organic diseases and other problems related to frailty increase anxiety and other types of psychological suffering.

Regarding self-perceived health, the association of poorer health and GAD is not directly proportional; individuals with this anxiety disorder will less frequently report their selfperceived health as very good or good. This finding in part may reflect the core characteristics of this syndrome, such as extremely high anxiety with worry and concerns related to everyday situations, accidents, diseases, and their own health; thereby all these symptoms can create a distortion in self-reporting measurements.
Finally, even though the sample had populational characteristics, all individuals were enrolled in the FHS, which could explain the high prevalence of GAD. This study presents associations with sociodemographic characteristics that were not examined previously in current literature and that should be further studied. Associations with gender, income, and health open possibilities for testing new hypotheses in GAD or other anxiety disorders in the elderly population in low and middle-income countries. Furthermore, improvements in the screening and mental diagnosis may lead to early intervention and better approaches that could lower costs for the health care system.

\section{CONCLUSIONS}

The data show a high prevalence of GAD in a representative sample of the elderly. Nevertheless, this disorder remains underdiagnosed and undertreated in the health primary care system. These epidemiological data from the Family Health Strategy are important to develop further strategies for this age group that could improve the health care practice. The screening of anxiety symptoms and syndromes in old people could lead to an early treatment that will improve life quality and could help to lower the health care system costs.

\section{LIMITATIONS}

This is a cross-sectional study, thereby it is possible to make associations but not possible to infer about causality between variables. The sample came from the FHS program, a public health facility that belongs to the Brazilian public health system that include predominantly individuals with lowincome resources. There is a high predominance of females in the sample, probably reflecting a more collaborative profile and greater health services use than compared with males. Despite free transportation offered to the subjects from FHS to the hospital, we had losses that came from the physical or mental disability. Therefore, this loss can be reduced if the trained team could go to these subjects' houses and apply all the assessments.

This study started when DSM IV was current. We had a few changes between GAD diagnoses criteria in the DSM-IV and the DSM-5. The DSM-IV criteria included that the anxiety and worry do not occur exclusively due to PTSD, a mood disorder, a psychotic disorder, or a pervasive developmental disorder. In DSM-5, this text was replaced by "the disturbance is not better explained by another mental disorder." Studies from the DSM-5 field trials of people-seeking treatment exhibited that there was a small but significant decrease in DSM-5 prevalence estimates of GAD when compared with the DSM-IV clinical diagnosis ${ }^{17}$. Nevertheless, the results must 
be interpreted with attention, because these findings were focused on assessments of treatment-seeking participants at only one of the seven field trial sites. The site-specific effects may affect the rates and the use of a treatment sample may not be extrapolated to a nationally representative household-based study ${ }^{18}$.

\section{INDIVIDUAL CONTRIBUTIONS}

Caroline Menta - Performed data collection, data analysis, and manuscript preparation.

Luísa Weber Bisol - Performed data analysis, and manuscript preparation.

Eduardo Lopes Nogueira-Performed project development, data collect, data analysis, and manuscript preparation.

Paula Engroff - Performed project development, data collection, data analysis, and manuscript preparation.

Alfredo Cataldo Neto - Performed project development, data collection, data analysis, and manuscript preparation.

\section{CONFLICT OF INTERESTS}

None.

\section{ACKNOWLEDGMENTS}

We thank our patients for being willing to participate in this study.

\section{REFERENCES}

1. World Health Organization (WHO). What are the public health implications of global aging? Geneva: World Health Organization; 2006. Available from: http://www.who.int/ features/qa/42/en/index.html. Accessed on: Dec 12, 2013.

2. Gonçalves DC, Pachana NA, Byrne GJ. Prevalence and correlates of generalized anxiety disorder among older adults in the Australian National Survey of Mental Health and WellBeing. J Affect Disord. 2011;132(1-2):223-30.
3. Roy-Byrne PP, Wagner A. Primary care perspectives on Generalized Anxiety Disorder. J Clin Psychiatry. 2004;65(13):20-6.

4. Boehlen FH, Herzog W, Schellberg D, Maatouk I, Schoettker B, Brenner H, et al. Genderspecific predictors of generalized anxiety disorder symptoms in older adults: Results of a large population-based study. J Affect Disord. 2020;262:174-81.

5. Andrews G, Hobbs MJ, Borkovec TD, Beesdo K, Craske MG, Heimberg RG, et al. Generalized worry disorder: a review of DSM-IV generalized anxiety disorder and options for DSM-V. Depress Anxiety. 2010;27(2):134-47.

6. Byers A, Yaffe K, Covinsky KE, Friedman MB, Bruce M. High occurrence of mood and anxiety disorders among older adults: The national comorbidity survey replication. Arch Gen Psychiatry. 2010;67(5):489-96.

7. Blay SL, Marinho V. Anxiety disorders in old age. Curr Opin Psychiatry. 2012;25(6):462-7.

8. Gomes I, Nogueira EL, Engroff P, Ely LS, Schwanke CHA, De Carli GA, et al. The multidimensional study of the elderly in the family health strategy in Porto Alegre, Brazil (EMI-SUS). Pan Am J Aging Res. 2013;1(1):20-4.

9. Kirmizioglu Y, Doğan 0, Kuğu N, Akyüz G. Prevalence of anxiety disorders among elderly people. Int J Geriatr Psychiatry. 2009;24(9):1026-33.

10. Wolitzky-Taylor KB, Castriotta N, Lenze EJ, Stanley MA, Craske MG. Anxiety disorders in older adults: a comprehensive review. Depress Anxiety. 2010;27(2):190-211.

11. Xavier FM, Ferraz MP, Moriguchi EH. Transtorno de ansiedade generalizada em idosos com oitenta anos ou mais. Rev Saúde Pública. 2001;35(3):294-302.

12. Remes 0 , Wainwright N, Surtees P, Lafortune L, Khaw KT, Brayne C. Generalised anxiety disorder and hospital admissions: findings from a large, population cohort study. BMJ Open. 2018;8(10):e018539.

13. Luppa M, Sikorski C, Motzek T, Konnopka A, König HH, Riedel-Heller SG. Health service utilization and costs of depressive symptoms in late life - a systematic review. Curr Pharm Des. 2012:18(36):5936-57.

14. Klassen BJ, Porcerelli JH, Markova T. The effects of PTSD symptoms on health care resource utilization in a low-income, urban primary care setting. J Trauma Stress. 2013;26(5):639-9.

15. Hallford DJ, Nicholson G, Sanders K, McCabe MP. The Association Between Anxiety and Falls: A Meta-Analysis. J Gerontol B Psychol Sci Soc Sci. 2017;72(5):729-41.

16. Friedman SM, Munoz B, West SK, Rubin GS, Fried LP. Falls and fear of falling: Which comes first? A longitudinal prediction model suggests strategies for primary and secondary prevention. J Am Geriatr Soc. 2002;50(8):1329-35.

17. Regier DA, Narrow WE, Clarke DE, Kraemer HC, Kuramoto SJ, Kuhl EA, et al. DSM-5 field trials in the United States and Canada, part ll: Test-retest reliability of selected categorical diagnoses. Am J Psychiatry. 2013;170(1):59-70.

18. Substance Abuse and Mental Health Services Administration. Impact of the DSM-IV to DSM-5 Changes on the National Survey on Drug Use and Health [Internet]. Rockville (MD): Substance Abuse and Mental Health Services Administration (US); 2016. [Mental IIIness]. Available from: https://www.ncbi.nlm.nih.gov/books/NBK519704/. 